\title{
Role of vasopressin and terlipressin in refractory shock compared to conventional therapy in the neonatal and pediatric population: a systematic review, meta- analysis, and trial sequential analysis
}

Reem Masarwa ${ }^{1,2}$, Gideon Paret ${ }^{3,4+}$, Amichai Perlman', Shimon Reif², Bruria Hirsh Raccah ${ }^{1}$ and llan Matok ${ }^{1 *+}$

\begin{abstract}
Background: Vasopressin (AVP) and terlipressin (TP) have been used as last-line therapy in refractory shock in children. However, the efficacy and safety profiles of AVP and TP have not been determined in pediatric refractory shock of different origins. We aimed to assess the efficacy and safety of the addition of AVP/TP therapy in pediatric refractory shock of all causes compared to conventional therapy with fluid resuscitation and vasopressor and inotropic therapy.
\end{abstract}

Methods: We conducted a systematic review, meta-analysis, and trial sequential analysis (TSA) comparing AVP and TP to conventional therapy. MEDLINE, EMBASE, Cochrane Library, and ClinicalTrials.gov were searched up to February 2016. The systematic review included all reports of AVP/TP use in the pediatric population. Reports of clinical trials were pooled using random-effects models and TSA. Main outcomes were mortality and tissue ischemia.

Results: Three randomized controlled trials and five "before-and-after clinical" trials (without comparator) met the inclusion criteria. Among 224 neonates and children (aged 0 to 18 years) with refractory shock, 152 received therapy with AVP or TP. Pooled analyses showed no association between AVP/TP treatment and mortality (relative risk (RR), 1.19; 95\% confidence interval (CI), 0.71-2.00), length of stay in the pediatric intensive care unit (PICU) (mean difference (MD), -3.58 days; $95 \% \mathrm{Cl},-9.05$ to 1.83 ), and tissue ischemia (RR, 1.48; 95\% Cl, 0.47-4.62). In TSA, no significant effect on mortality and risk for developing tissue ischemia was observed with AVP/TP therapy.

Conclusion: Our results emphasize the lack of observed benefit for AVP/TP in terms of mortality and length of stay in the PICU, and suggest an increased risk for ischemic events. Our TSA suggests that further large studies are necessary to demonstrate and establish benefits of AVP/TP in children.

PROSPERO registry: CRD42016035872

Keywords: Vasopressin (AVP), Terlipressin (TP), Shock, Septic, Refractory, Vasodilatory, Refractory hypotension, Pediatrics

\footnotetext{
* Correspondence: ilan.matok@ekmd.huji.ac.il

${ }^{\dagger}$ Equal contributors

${ }^{1}$ Division of Clinical Pharmacy, School of Pharmacy, Faculty of Medicine, The

Hebrew University of Jerusalem, Jerusalem, Israel

Full list of author information is available at the end of the article
} 


\section{Background}

Hemodynamic shock is a leading cause of morbidity and mortality in the pediatric population worldwide [1]. A delay in treating shock may result in irreversible organ damage [2, 3]. Morbidity from shock may include renal failure, disseminated intravascular coagulation (DIC), and death [1-3]. Early goal-directed therapy is targeted at maintaining and restoring an adequate ventilation and circulation within the first hour of shock onset [4-6].

Aggressive fluid resuscitation is the first line of therapy for shock [7]. Thereafter, hemodynamic support is achieved with vasopressors and inotropes [5, 7]. However, reduced vasoconstrictor sensitivity to vasopressors in shock can lead to vasodilation, severe hypotension, and vasoparalysis [8]. There is, therefore, a pressing need for agents which target other pathways involved in the development of shock.

In the past decade, arginine-vasopressin (AVP) has emerged as a potentially useful therapy for refractory shock [9]. AVP acts on V1 receptors located on vascular smooth muscle leading to an increase in mean arterial pressure (MAP). Patients with shock exhibit inappropriately low circulating AVP concentrations [7, 8, 10]. From a biologic perspective, the basic rationale behind the addition of AVP/TP in refractory shock is the depletion of endovascular AVP in states of shock [11]. Furthermore, AVP/terlipressin (TP) may contribute to MAP elevation in the refractory shock state since vascular smooth muscle shows a decreased ability to contract, and the hypotension may be refractory to standard catecholamine vasopressor therapy [12].

AVP and TP administration in states of shock may be beneficial in improving cardiovascular parameters, such as MAP and heart rate (HR) $[13,14]$. AVP/TP may also be used in vasodilatory shock following cardiopulmonary bypass [15].

There is a paucity of data regarding the outcomes of the use of AVP/TP in refractory shock in children. A Cochrane review from 2013, which aimed to assess the efficacy and safety of AVP in neonates with refractory shock, did not find sufficient evidence to recommend or refute the use of AVP [16]. We therefore sought to conduct a systematic review, meta-analysis, and trial sequential analysis (TSA) to evaluate the efficacy and safety of AVP/TP in critically ill neonates and children with refractory shock of different origins compared to conventional therapy with fluid resuscitation, vasopressor, and inotropic therapy.

\section{Methods}

\section{Data sources and searches}

This systematic review followed the Preferred Reporting Items for Systematic Reviews and Meta-analysis (PRISMA 2009) framework guidelines and the review protocol was registered at the PROSPERO registry of systematic reviews on February 2016 (registry number: CRD 42016035872) $[17,18]$. The systematic review was performed using MEDLINE, EMBASE, and Cochrane through February 2016 to identify all published randomized controlled trials (RCTs), prospective clinical trials ("before and after", without a comparator group), cohort studies, casecontrol studies, and case series involving the treatment/ comparison of AVP or TP (in addition to conventional therapy) in pediatric refractory shock (of septic, vasodilatory, or mixed origin) to conventional therapy. Relevant studies were identified using the following search terms: "vasopressin", "terlipressin", "shock", "septic", "refractory", "hypotension", "vasodilatory", "mixed", "children", "neonates". We subsequently searched and evaluated published systematic reviews, online resources, conference abstracts, clinicaltrials.gov, and expert opinion to ensure identification of all published and unpublished studies. No language or date restrictions were applied to the search. No approval from the Institutional Review Board was required.

\section{Study selection and data extraction}

The studies were identified through a search by one reviewer (RM), and the abstracts were independently screened by two reviewers (RM and BHR). Disagreements were resolved by consensus and/or referral to a third reviewer (IM). The full text of the resulting references was then retrieved by one reviewer (RM). The primary endpoints of this analysis were mortality outcomes (30-day mortality in RCTs or mortality during/by end of trial in non-RCTs) and tissue ischemia (new onset or worsening of existing condition). Secondary outcomes included hemodynamic indices, vasoactive score, and the length of stay in the pediatric intensive care unit (PICU).

\section{Selection criteria}

We applied the following screening criteria to determine qualitative eligibility for inclusion in the meta-analysis: prospective clinical studies (RCTs and prospective "before and after " clinical trials, without comparator group) of children aged 0 to 18 years and in refractory shock, which compared AVP/TP (in addition to conventional therapy) to conventional therapy and reported on mortality, morbidity, at least two hemodynamic indices, and adverse effects, and which met $1 b$ and $1 c$ levels of evidence of the Oxford Centre for Evidence-based Medicine (CEBM) levels of evidence 2011 [19]. We excluded studies of AVP/ TP for other indications, or with no full-text access. Retrospective and prospective observational studies and case reports were included in the systematic review only.

\section{Quality assessment and risk of bias}

The methodological quality of the studies included was assessed using the CEBM levels of evidence 2011 [19]. 
Risk of bias was assessed according to the Cochrane Collaboration methodology [20].

\section{Data synthesis}

We conducted a meta-analysis to pool the results of trials comparing conventional therapy only with conventional therapy plus AVP/TP using Comprehensive Metaanalysis (CMA 3.0). For TSA, the TSA program v.0.9 beta was used (http://www.ctu.dk/tsa/downloads.aspx). For bias risk assessment we used Review Manager (RevMan), Version 5.3. Copenhagen (The Nordic Cochrane Centre, The Cochrane Collaboration, 2014). The primary comparison themes were mortality and tissue ischemia. Secondary comparison themes included vasoactive score, the length of stay in the PICU, and hemodynamic measures. For studies reporting only the interquartile range (IQR) for continuous measure outcomes, we assumed that the mean and median were equal, and calculated the standard deviation (SD) from IQR by dividing the IQR by 1.35 [21]. To calculate the change in continuous hemodynamic measures we estimated the standard deviation from the pooled variance of each measure. Heterogeneity was assessed using the $I^{2}$ statistic. Values of $25 \%, 50 \%$, and $75 \%$ for $I^{2}$ represented low, medium, and high heterogeneity, respectively [22]. We used random-effects models to pool results. We calculated risk ratios (RRs) for dichotomous outcomes when including only RCTs in the analysis. Event rates (ERs) were calculated for dichotomous outcomes including RCTs and "before-and-after clinical" trials (without comparator). Event rates are a measure of how often an event occurred in a group [23], and are measures of the occurrence of an event for each participant over the time they were observed. Pooled event rates from the "before and after" clinical trials can provide an estimate of the expected rates of these events in the settings evaluated; however, they do not provide a direct estimate of the relative effect of the intervention compared to a control. The mean difference (MD) was calculated for continuous outcomes, with their corresponding 95\% confidence intervals (CIs). Statistical significance was defined using a two-sided $\alpha$ of 0.05 , and interpretations of clinical significance emphasized CIs.

\section{Trial sequential analysis}

Meta-analyses may result in type I errors owing to an increased risk of random error when sparse data are analyzed [24]. TSA allows for controlling the $p$ value when scarce data exist and clear conclusions cannot be drawn $[25,26]$. TSA allows the quantification of the required sample size for determining the effect under study while adjusting the threshold for statistical significance [25, 26]. The threshold for reaching statistical significance adjusts the CIs and reduces type I errors. When the cumulative z-curve crosses the threshold boundaries, one may conclude that a sufficient level of evidence for the intervention effect has been reached and no further trials are needed. If the z-curve does not cross any of the boundaries, evidence to reach a conclusion is insufficient [25]. We used TSA adjusted random-effects models to pool results from RCTs for primary outcomes. We conducted two- and one-sided TSA to maintain a risk of $5 \%$ for type I error and a power of $80 \%$. We used the estimated function to calculate the required information size (IS). We calculated 95\% CIs adjusted for repetitive testing.

\section{Results}

Trial flow

Our search yielded 140 relevant titles. Initial screening led to the exclusion of 18 duplicate records and 72 records that did not meet inclusion criteria. The remaining 50 publications were retrieved for full-text review. Twenty-two publications were excluded based on inclusion criteria, leaving 28 studies. Twenty studies were observational and were included in the systematic review only (Additional file 1: Table S1), leaving eight clinical publications for meta-analysis. The selection process is illustrated in Fig. 1.

\section{Characteristics and quality of clinical studies included in the meta-analysis}

The studies included in the analysis are detailed in Table 1 . In total, 224 children received AVP/TP. In all reports, conventional therapy with volume resuscitation and vasopressors/inotropes were given prior to the initiation of AVP/TP (excluding one study which included volume resuscitation or dopamine) [27]. Three RCTs [27-29] and five clinical trials [30-34] met the $1 \mathrm{~b}$ and 1c level criteria of the CEBM [19], and two RCTs had a low risk for bias (Additional file 2: Figure S1) [27, 29]. The studies included evaluated the effect of AVP/TP in the pediatric population over a relatively wide range of ages, and the majority of the studies were not restricted to shock arising from a specific mechanism.

\section{Meta-analysis \\ Mortality}

The addition of AVP/TP to vasopressor/inotropic therapy in refractory shock had no significant effect on mortality. Analysis of RCTs resulted in a non-significant difference in risk compared to conventional treatment, with a RR of 1.19 with low heterogeneity (95\% CI, 0.71$2.00 ; I^{2}=28 \%$ ) (Fig. 2). The mortality rate among patients treated with AVP/TP in the clinical trials was high, with a pooled ER of 0.49 (95\% CI, 0.37-0.61) (Fig. 3). In TSA, the boundary for futility was not crossed, and no effect on mortality was observed; the estimated IS to 


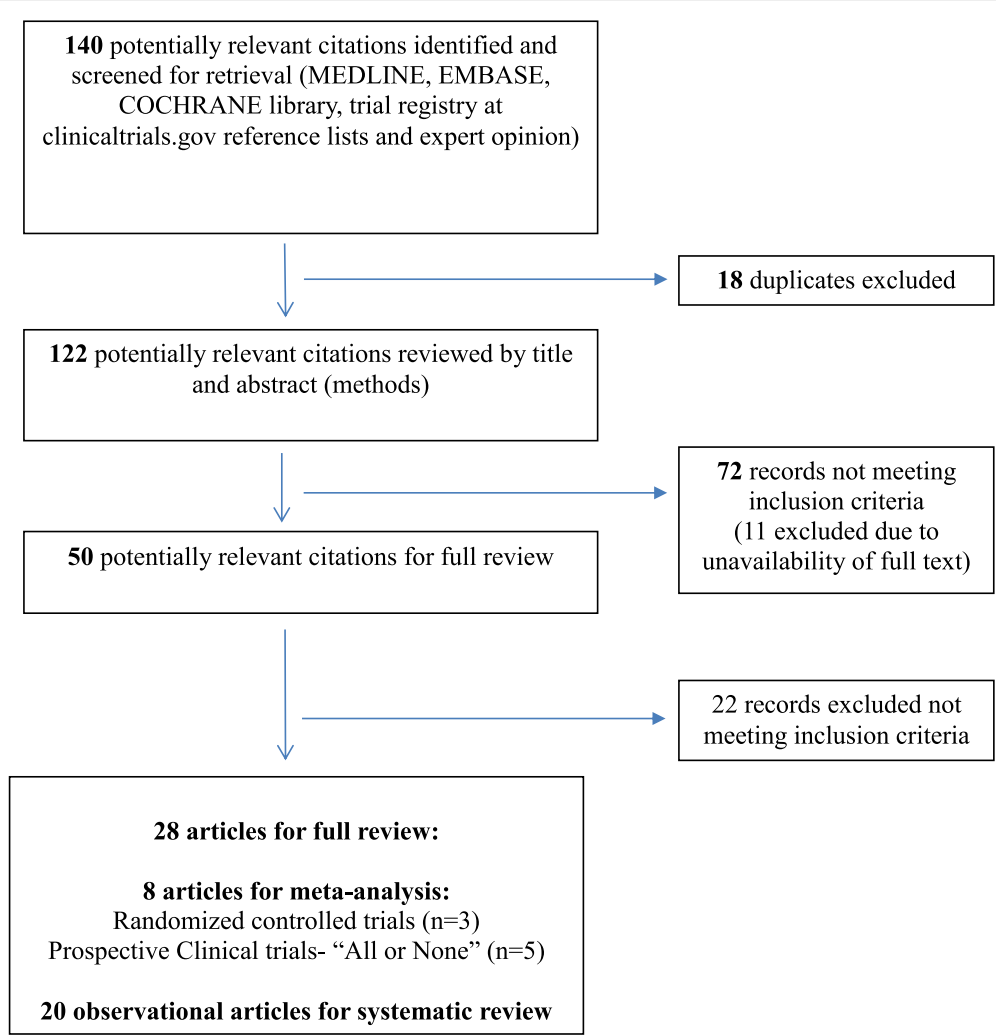

Fig. 1 Publication selection and search process

reach the futility boundaries was 392 randomized patients (Fig. 4).

\section{Tissue ischemia}

The addition of AVP/TP to vasopressor/inotropic therapy in refractory shock had no significant effect on the risk for developing tissue ischemia. Analysis of $\mathrm{RCTs}$ resulted in a non-significant difference in risk compared to conventional treatment, with a RR of 1.48 with low heterogeneity (95\% CI, 0.47-4.62; $I^{2}=0 \%$ ) (Fig. 5). The tissue ischemia rate among patients treated with AVP/TP in the clinical trials was considerable, with a pooled ER of 0.16 (95\% CI, 0.08-0.28) (Additional file 3: Figure S2). In TSA, the boundary for futility was not crossed, and no effect on tissue ischemia was observed; the estimated IS to reach the futility boundaries was 231 randomized patients (Additional file 4: Figure S3).

\section{Vasoactive score}

The addition of AVP/TP in refractory shock resulted in a significant decrease in the vasoactive score compared to standard therapy, with a pooled MD of -14.13 units and low heterogeneity (95\% CI, -20.61 to -7.66 ; $I^{2}=38.25 \%$ ) (Additional file 5: Figure S4).

\section{Mean arterial pressure}

The addition of AVP/TP in refractory shock resulted in a significant increase in the MAP, with a pooled MD of $12.34 \mathrm{mmHg}$ and high heterogeneity $(95 \% \mathrm{CI}, 6.38-18.3$; $I^{2}=93 \%$ ) (Additional file 6: Figure S5).

\section{Heart rate}

The addition of AVP/TP in refractory shock resulted in a significant decrease in the HR, with a pooled MD of 12.25 beats per minute and intermediate heterogeneity (95\% CI, -18.96 to $-5.55 ; I^{2}=67 \%$ ) (Additional file 7 : Figure S6).

\section{Length of stay in the PICU}

The addition of AVP/TP in refractory shock did not result in a significant decrease in the length of stay, with a pooled MD of -3.58 days (reduction) and intermediate heterogeneity (95\% CI, -9.05 to $\left.1.83 ; I^{2}=54 \%\right)$ (Additional file 8: Figure S7).

\section{Discussion}

In this meta-analysis, no significant difference in mortality risk was found between AVP/TP and conventional treatment for refractory shock in the pediatric population. Furthermore, after applying TSA, the non-significant effect 


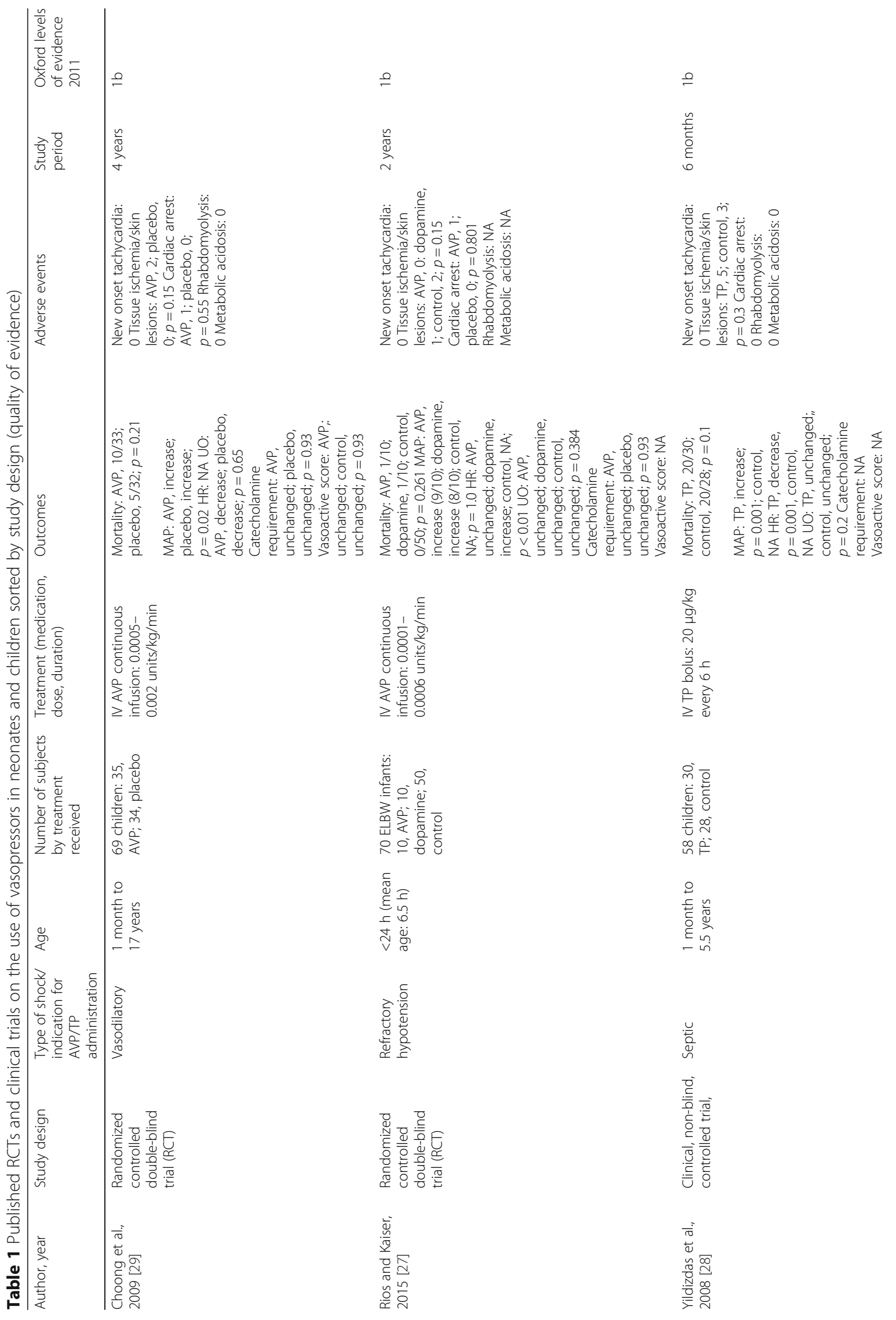




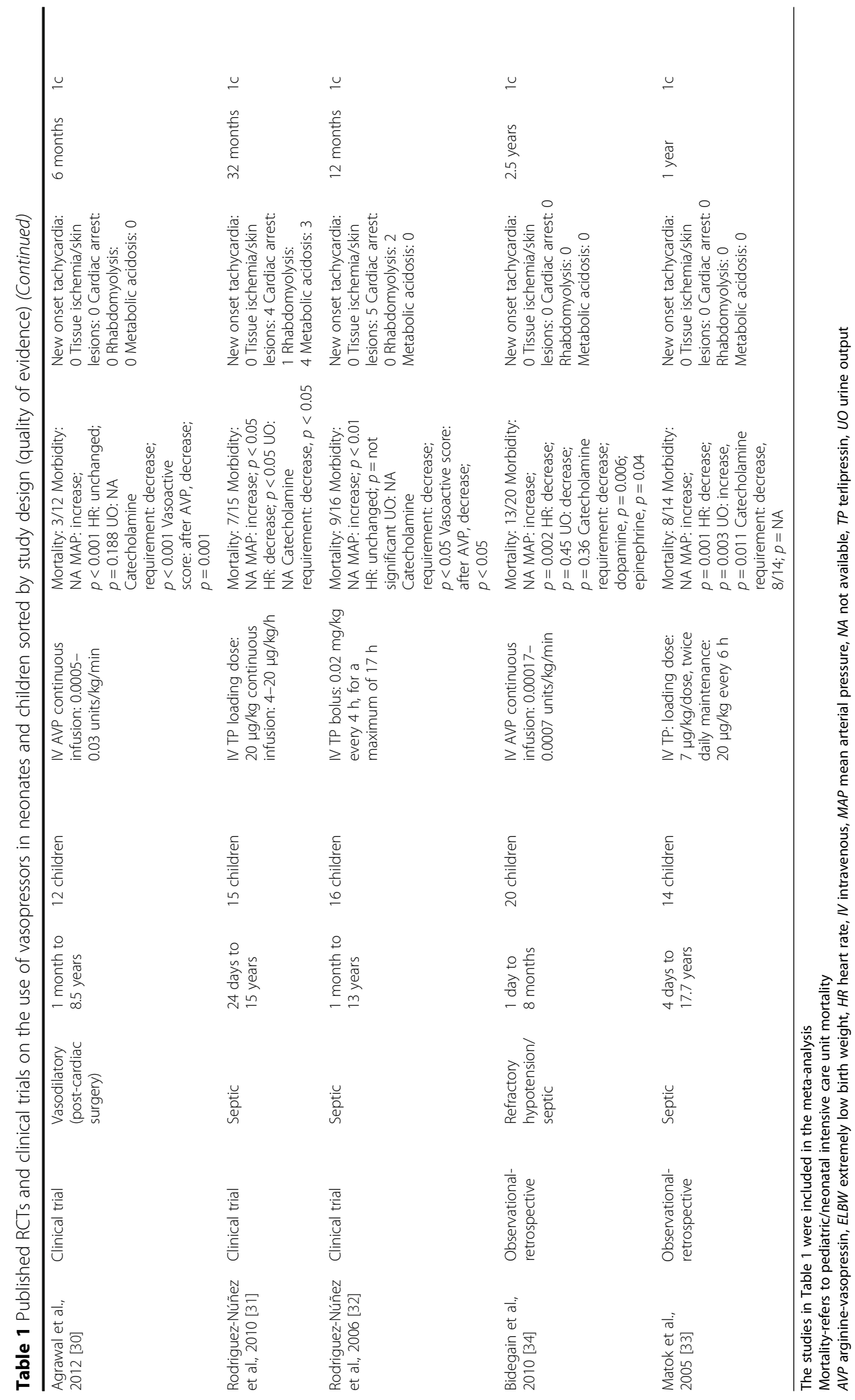




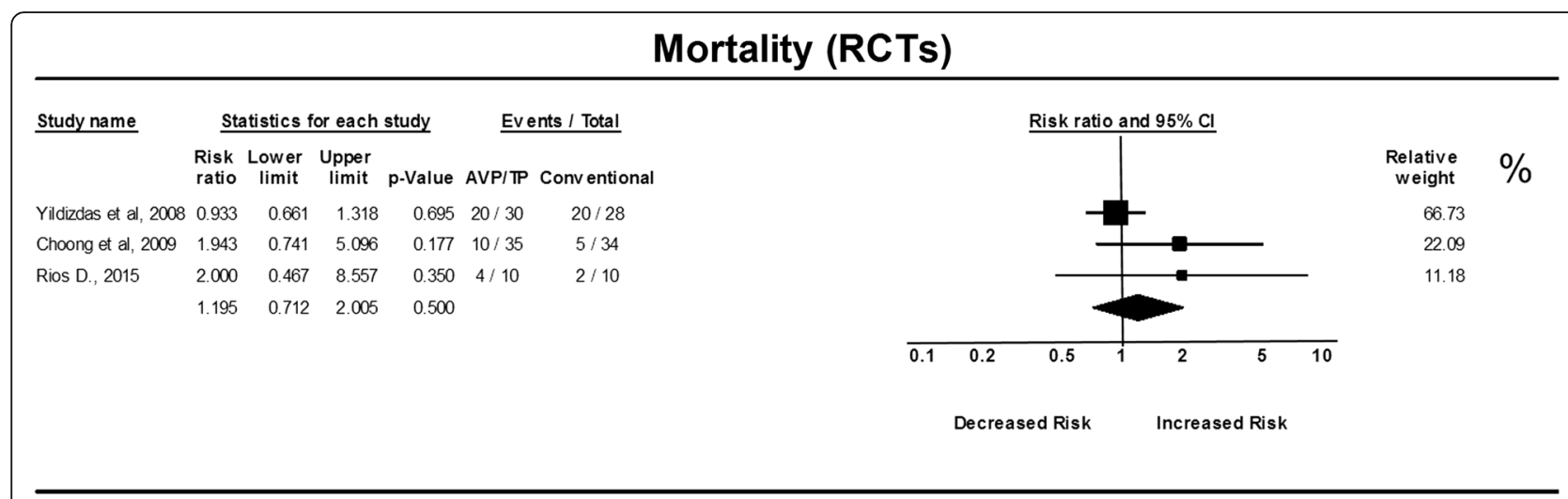

Heterogeneity- Q-value:2.76, df:2, p-value:0.251, l-squared:27.73\%

Fig. 2 The risk ratio for mortality in randomized controlled trials $(R C T s)$. The forest plot demonstrates point estimates of risk ratio surrounded by 95\% confidence interval (CD). AVP arginine-vasopressin, TP terlipressin

on mortality outcomes remained; however, a large number of randomized patients would be required to reach the futility boundary. Although no significant difference in tissue ischemia risk was found, when applying TSA we found a trend towards a higher risk for tissue ischemia.

$\mathrm{AVP} / \mathrm{TP}$ treatment did significantly improve hemodynamic indices, with a significant reduction in the vasoactive score, HR, and an increase in MAP.

Our meta-analysis indicates that AVP/TP therapy is ineffective in reducing mortality in refractory shock in the pediatric population. Our results demonstrate that mortality rates among patients treated with AVP/TP in the clinical trials were high, as evidenced by the pooled ER estimate for mortality. Moreover, analysis of RCTs resulted in a non-significant difference in the relative risk for death between the treatment and control groups. The high mortality rates in the studies included in our analysis can be attributed to the high risk for mortality characteristic of refractory shock despite proper treatment [4]. However, our results indicate that a very large

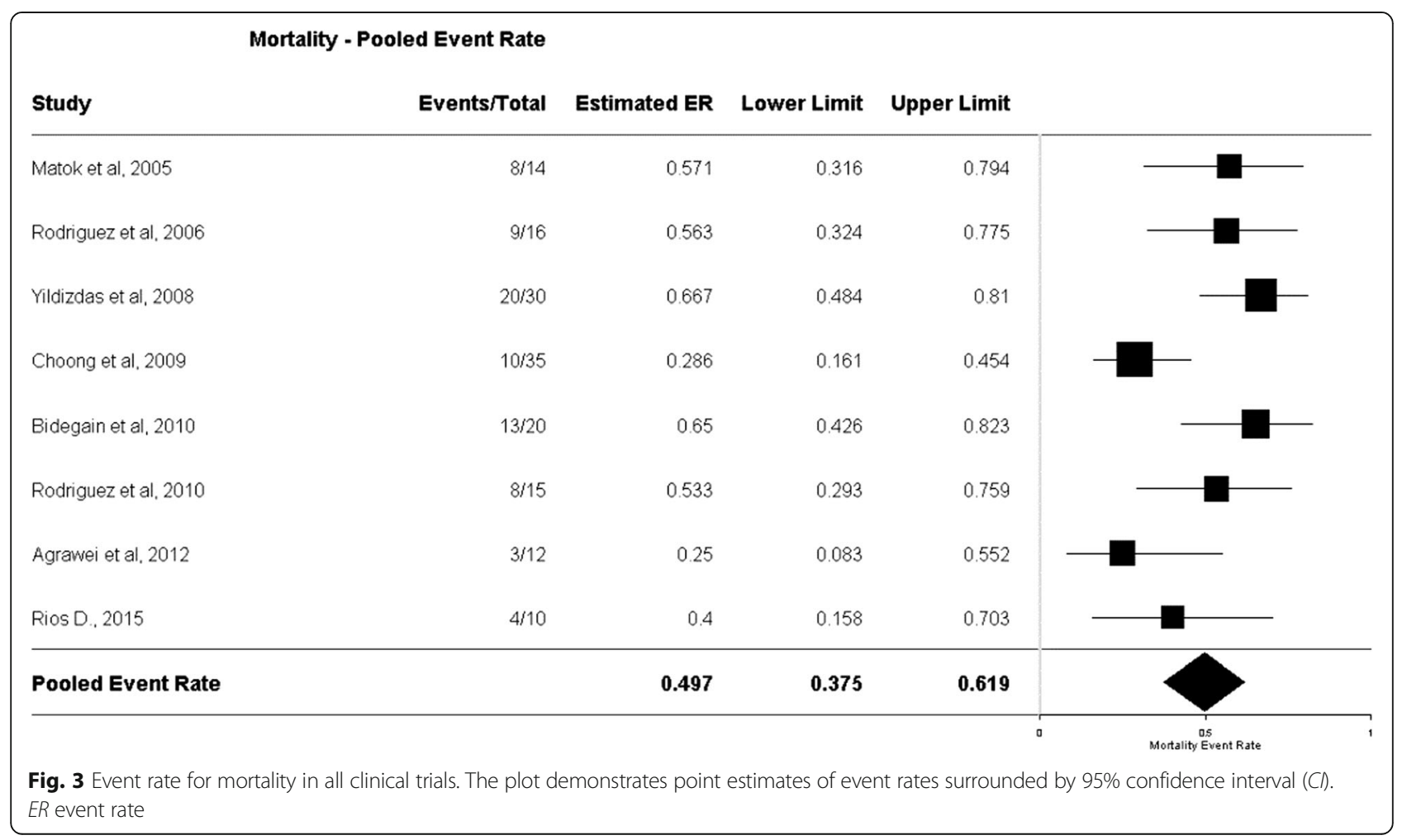




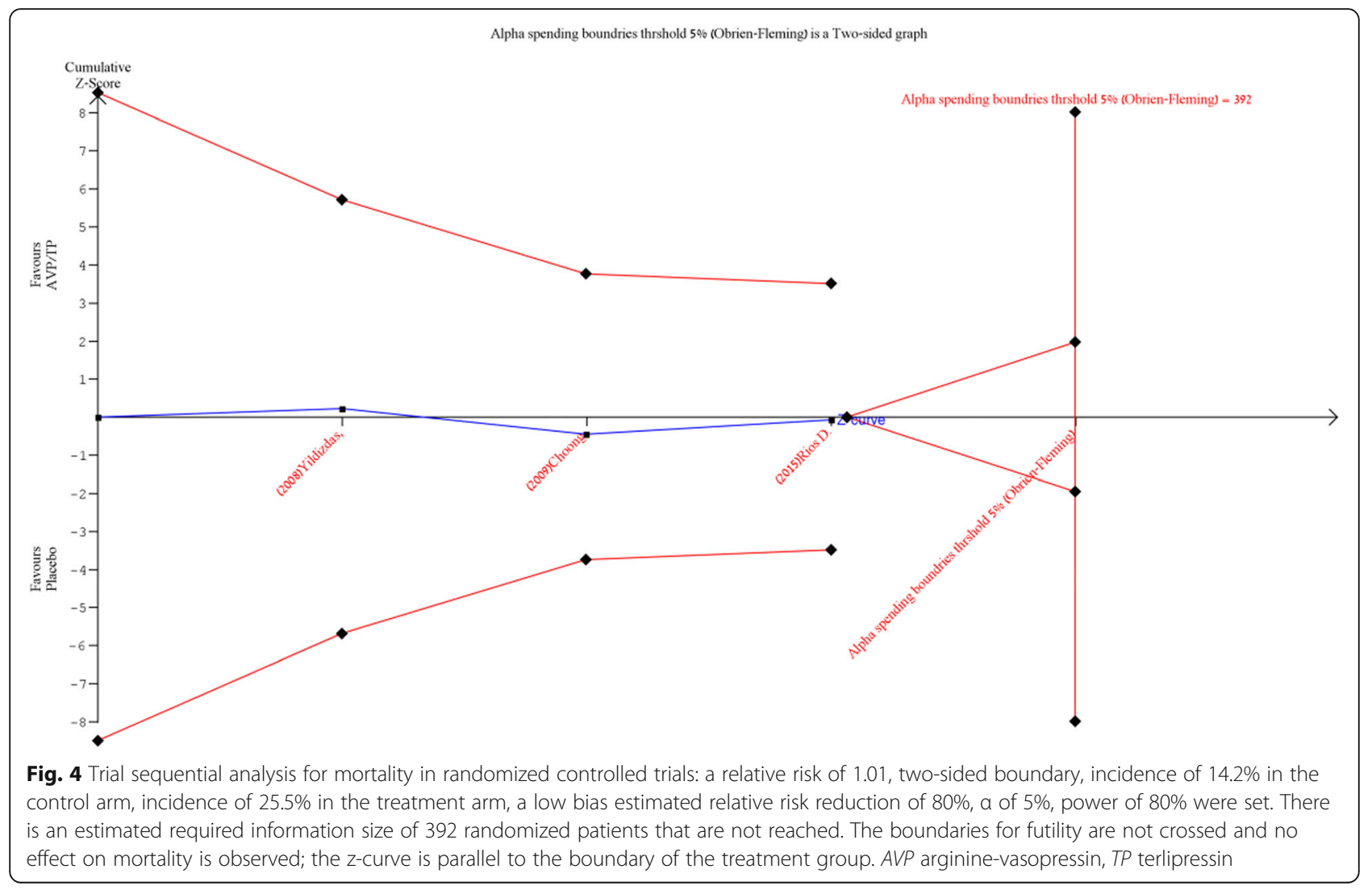

number of patients would be necessary to reach the information size required to reach the futility boundaries for mortality, as shown by TSA.

AVP acts on V1 receptors located on vascular smooth muscle leading to vasoconstriction, and therefore therapy with AVP/TP may put the patients at a higher risk for developing tissue ischemia [9]. In adults, RCTs showed a trend towards developing tissue ischemia with $\mathrm{AVP} / \mathrm{TP}$ therapy $[35,36]$. Our meta-analysis found high event rates for tissue ischemia among AVP/TP-treated patients.

The vasoactive score has previously been shown to be associated with morbidity and mortality in PICUs [37, 38],

\section{Tissue Ischemia (RCTs)}

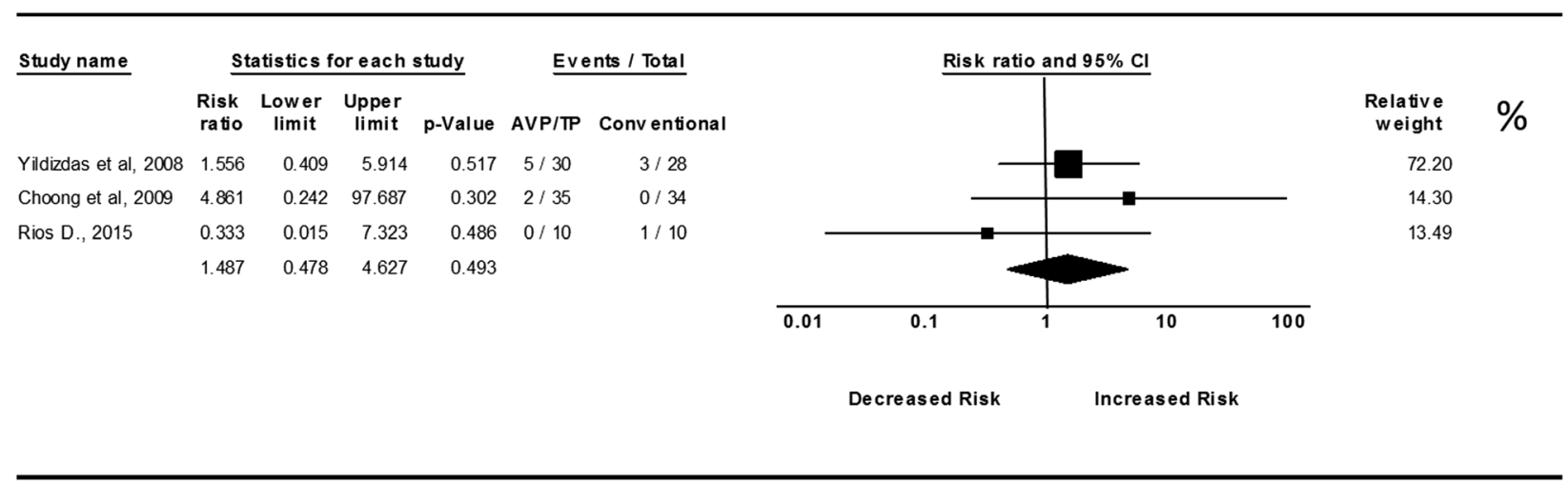

Heterogeneity- Q-value:1.5, df:2, p-value:0.472, l-squared:0.0001\%

Fig. 5 The risk ratio for tissue ischemia in randomized controlled trials (RCTs). The forest plot demonstrates point estimates of risk ratio surrounded by $95 \%$ confidence interval (CI). AVP arginine-vasopressin, TP terlipressin 
and also has been associated with improvement in length of stay in the PICU [38]. Although AVP/TP treatment resulted in lower vasoactive scores, it did not significantly reduce clinically important outcomes such as mortality and the length of stay in the PICU.

Our analysis found a significant increase in MAP and a decrease in HR, in line with previous reports. These effects may be attributed to the mechanism by which AVP/TP causes vasoconstriction, and to the decreased sensitivity of vascular smooth muscle to catecholamines in refractory shock [37-39]. However, this did not seem to translate into a meaningful improvement in clinically significant outcomes.

Unfortunately, most of the studies included in our meta-analysis did not address the mechanism of shock and did not report on performing echocardiography during the study period, and, consequently, may have included patients with different mechanisms of shock. In light of the absence of information regarding ventricular function in most of the studies identified, and the fact that the outcome of neonatal and pediatric shock relies on ventricular function, we were unable to assess the relationship between the mechanism of shock and goal of treatment and the effectiveness of AVP/TP. As AVP and TP do not possess inotropic properties they are far less likely to be of use in states of shock where ventricular dysfunction is present. Additionally, the meta-analysis included studies with children of different ages. As scarce high-quality literature exists regarding the use of AVP/TP in neonates and children with refractory shock, a separate statistical analysis for neonates and children was not feasible. Our results are therefore limited by the nature of the available studies, as there may be difference between neonates and older children, and between different types of shock, regarding the mechanism of shock compensation and drug doses, as well as the potential for adverse effects. For example, the presence of DIC in refractory shock is probably higher than less severe types of shock, and AVP/TP is more likely to provide benefit in vasodilatory shock compared to cardiogenic shock [40].

\section{Conclusion}

The results of our analysis emphasize the lack of observed benefit for AVP/TP in terms of mortality, as well as a possible association with ischemic events. While the data available on this topic are limited, and the possibility of a small benefit cannot be ruled out, our trial sequential analysis suggests that further studies are unlikely to demonstrate an improvement in mortality; however, more studies would be necessary to demonstrate this conclusively. Additionally, further studies of AVP/TP incorporating an evaluation of the mechanism of shock could enhance our understanding of the clinical utility of AVP/TP for specific types of shock.

We believe these findings are quite important, as they can both inform current practitioners as to the best available evidence regarding the efficacy and safety of these agents.

\section{Additional files} Additional file 1: Table S1. Published observational reports on the use
of vasopressors in neonates and children. (DOCX $42 \mathrm{~kb}$ )

Additional file 2: Figure S1. Risk of bias summary: review authors' judgements about each risk of bias item for each included study. (DOCX $23 \mathrm{~kb}$ )

Additional file 3: Figure S2. Event rate for tissue ischemia in all clinical trials. The plot demonstrates point estimates of event rate surrounded by 95\% Cl. (DOCX $48 \mathrm{~kb})$

Additional file 4: Figure S3. Trial sequential analysis for tissue ischemia in randomized controlled trials. A relative risk of 2.72 , one-sided lower boundary, an incidence of $1.6 \%$ in the control arm, an incidence of $11 \%$ in the treatment arm, a low bias estimated relative risk reduction of $85 \%$, a of $5 \%$, power of $80 \%$ were set. An estimated required information size of 231 randomized patients was not reached. The boundaries for futility are not crossed and no effect on tissue ischemia is observed. (DOCX $120 \mathrm{~kb}$ )

Additional file 5: Figure S4. Mean difference for vasoactive score. The forest plot demonstrates point estimates of mean difference surrounded by $95 \% \mathrm{Cl}$. (DOCX $138 \mathrm{~kb}$ )

Additional file 6: Figure S5. Mean difference for mean arterial pressure. The forest plot demonstrates point estimates of mean difference surrounded by $95 \% \mathrm{Cl}$. (DOCX $155 \mathrm{~kb}$ )

Additional file 7: Figure S6. Mean difference for heart rate. The forest plot demonstrates point estimates of mean difference surrounded by 95\% Cl. (DOCX $153 \mathrm{~kb}$ )

Additional file 8: Figure S7. Mean difference for length of stay in intensive care. The forest plot demonstrates point estimates of mean difference surrounded by $95 \% \mathrm{Cl}$. (DOCX $133 \mathrm{~kb}$ )

\section{Abbreviations}

AVP: Arginine-vasopressin; CEBM: Center for Evidence-based Medicine; $\mathrm{Cl}$ : Confidence interval; CMA: Comprehensive Meta-analysis; DIC: Disseminated intravascular coagulation; ER: Event rate; HR: Heart rate; IQR: Interquartile range; IS: Information size; MAP: Mean arterial pressure; MD: Mean difference; PICU: Pediatric intensive care unit; RCT: Randomized controlled trial; RR: Risk ratio; TP: Terlipressin; TSA: Trial sequential analysis

\section{Acknowledgements}

No external funding was used for this study.

\section{Funding}

The authors have not received any financial funding by any company that manufactures vasopressin or terlipressin.

\section{Availability of data and material}

Not applicable.

\section{Authors' contribution}

RM had full access to all of the data in the study and takes responsibility for the integrity of the data and the accuracy of the data analysis. RM contributed to study design, the collection of data and data analysis, and wrote the first draft of the manuscript. IM directed the research, contributed to study design, analysis of data, interpretation of study results, and writing of the manuscript. AP contributed substantially to the study concept and to the drafting and revision of the manuscript. BHR contributed to the literature search and the critical appraisal of the manuscript. GP and SR both provided 
critical appraisal and revision, and contributed substantially to study interpretation. All authors reviewed and approved the final manuscript.

\section{Competing interests}

The authors declare that they have no competing interests.

\section{Consent for publication}

Not applicable.

\section{Ethics approval and consent to participate}

No ethics committee approval was required for our research.

\section{Author details}

${ }^{1}$ Division of Clinical Pharmacy, School of Pharmacy, Faculty of Medicine, The Hebrew University of Jerusalem, Jerusalem, Israel. '2Department of Pediatrics, Hadassah-Hebrew University Medical Center, Ein-Kerem, Jerusalem, Israel. ${ }^{3}$ Department of Pediatric Intensive Care Medicine, Safra Children's Hospital, Chaim Sheba Medical Center, Ramat-Gan, Israel. ${ }^{4}$ Sackler Faculty of Medicine, Tel Aviv University, Tel-Aviv, Israel.

Received: 8 August 2016 Accepted: 12 December 2016

Published online: 05 January 2017

\section{References}

1. Ranjit-Rogers S, Nadel S, Kissoon N. Recognition and initial management of shock. In: Nichols DGR, editor. Textbook of pediatric intensive care. Philadelphia: Lippincott, William \& Wilkins; 2008. p. 372-83.

2. Epstein C, Randall D. Cardiovascular physiology and shock. In: Nichols DG, editor. Critical heart disease in infants and children. 2nd ed. Philadelphia: Mosby Elsevier; 2006. p. 17-72.

3. Smith L, Hernan LS. Shock states. In: Fuhrman J, Zimmerman BP, editors Pediatric critical care. 4th ed. Philadelphia: Elsevier Saunders; 2011. p. 364-378.

4. Watson RS, Carcillo JA, Linde-Zwirble WT, Clermont G, Lidicker J, Angus DC. The epidemiology of severe sepsis in children in the United States. Am J Respir Crit Care Med. 2003;167(5):695-701.

5. Weiss SL, Fitzgerald JC, Pappachan J, Wheeler D, Jaramillo-Bustamante JC, Salloo A, Singhi SC, Erickson S, Roy JA, Bush JL, Nadkarni VM, Thomas NJ. Global epidemiology of pediatric severe sepsis: the sepsis prevalence, outcomes, and therapies study. Am J Respir Crit Care Med. 2015;191(10):1147-57.

6. Brierley J, Carcillo JA, Choong K, Cornell T, Decaen A, Deymann A, Doctor A, Davis A, Duff J, Dugas M-A, Duncan A, Evans B, Feldman J, Felmet K, Fisher G, Frankel L, Jeffries H, Greenwald B, Gutierrez J, Hall M, Han YY, Hanson J, Hazelzet J, Hernan L, Kiff J, Kissoon N, Kon A, Irazuzta J, Irazusta J, Lin J, Lorts A, Mariscalco M, Mehta R, Nadel S, Nguyen T, Nicholson C, Peters M, Okhuysen-Cawley R, Poulton T, Relves M, Rodriguez A, Rozenfeld R, Schnitzler E, Shanley T, Kache S, Skache S, Skippen P, Torres A, von Dessauer B, Weingarten J, Yeh T, Zaritsky A, Stojadinovic B, Zimmerman J, Zuckerberg A. Clinical practice parameters for hemodynamic support of pediatric and neonatal septic shock: 2007 update from the American College of Critical Care Medicine. Crit Care Med. 2009;37(2):666-88.

7. Obritsch MD, Bestul DJ, Jung R, Fish DN, MacLaren R. The role of vasopressin in vasodilatory septic shock. Pharmacotherapy. 2004;24:1050-63.

8. Meyer S, McGuire W, Gottschling S, Mohammed Shamdeen G, Gortner L. The role of vasopressin and terlipressin in catecholamine-resistant shock and cardio-circulatory arrest in children: review of the literature. Wien Med Wochenschr. 2011;161:192-203

9. Holmes $\mathrm{CL}$, Patel BM, Russell JA, Walley KR. Physiology of vasopressin relevant to management of septic shock. Chest. 2001:120:989-1002.

10. Polito A, Parisini E, Ricci Z, Picardo S, Annane D. Vasopressin for treatment of vasodilatory shock: an ESICM systematic review and meta-analysis. Intensive Care Med. 2012;38:9-19.

11. Landry DW, Oliver JA. The pathogenesis of vasodilatory shock. N Engl J Med. 2001;345:588-95.

12. Barrett LK, Singer M, Clapp LH. Vasopressin: mechanisms of action on the vasculature in health and in septic shock. Crit Care Med. 2007:35(1):33-40.

13. O'Brien A, Clapp L, Singer M. Terlipressin for norepinephrine-resistant septic shock. Lancet. 2002:359:1209-10.

14. Dellinger RP, Levy MM, Rhodes A, Annane D, Gerlach H, Opal SM, Sevransky JE, Sprung $\mathrm{CL}$, Douglas IS, Jaeschke R, Osborn TM, Nunnally ME, Townsend SR, Reinhart K, Kleinpell RM, Angus DC, Deutschman CS, Machado FR,
Rubenfeld GD, Webb SA, Beale RJ, Vincent J-L, Moreno R. Surviving sepsis campaign: international guidelines for management of severe sepsis and septic shock: 2012. Crit Care Med. 2013;41:580-637.

15. Argenziano M, Choudhri AF, Oz MC, Rose EA, Smith CR, Landry DW. A prospective randomized trial of arginine vasopressin in the treatment of vasodilatory shock after left ventricular assist device placement. Circulation. 1997;2:286-90

16. Shivanna B, Rios D, Rossano J, Fernandes CJ, Pammi M. Vasopressin and its analogues for the treatment of refractory hypotension in neonates. Cochrane Database Syst Rev. 2013;3(3):CD009171.

17. PROSPERO International Prospective Register of Systematic Reviews. Available at: www.crd.york.ac.uk/Prospero. Accessed: 28 Feb 2016.

18. Transport Reporting Of Systematic Reviews and Meta-Analyses, "PRISMA 2009 Checklist." Available at: http://www.prisma-statement.org/documents/ PRISMA\%202009\%20checklist.pdf. Accessed: 20 Jan 2016.

19. OCEBM Levels of Evidence Working Group. OCEBM Levels of Evidence Working Group. 'The Oxford 2011 Levels of Evidence'. Oxford Cent Evidence-Based Med. 2011;1:5653.

20. Higgins JPT, Altman DG, Gotzsche PC, Juni P, Moher D, Oxman AD, Savovic J, Schulz KF, Weeks L, Sterne JC. The Cochrane Collaboration's tool for assessing risk of bias in randomised trials. BMJ. 2011;343:d5928.

21. Wan X, Wang W, Liu J, Tong T. Estimating the sample mean and standard deviation from the sample size, median, range and/or interquartile range. BMC Med Res Meth. 2014;14:135.

22. Higgins JPT, Thompson SG. Quantifying heterogeneity in a meta-analysis. Stat Med. 2002;21(11):1539-58.

23. OCEBM Levels of Evidence Working Group. Experimental event rate (EER), University of Oxford. Available at: http://www.cebm.net/glossary/. Accessed 20 Sep 2016.

24. Turner RM, Bird SM, Higgins JPT. The impact of study size on meta-analyses: examination of underpowered studies in Cochrane reviews. PLoS One. 2013:8:e59202.

25. Wetterslev J, Thorlund K, Brok J, Gluud C. Trial sequential analysis may establish when firm evidence is reached in cumulative meta-analysis. J Clin Epidemiol. 2008;61:64-75.

26. Wetterslev J, Thorlund K, Brok J, Gluud C. Estimating required information size by quantifying diversity in random-effects model meta-analyses. BMC Med Res Methodol. 2009:9:86.

27. Rios DR, Kaiser JR. Vasopressin versus dopamine for treatment of hypotension in extremely low birth weight infants: a randomized, blinded pilot study. The Journal of Pediatrics. 2015;166(4):850-55.

28. Yildizdas D, Yapicioglu H, Celik U, Sertdemir Y, Alhan E. Terlipressin as a rescue therapy for catecholamine-resistant septic shock in children. Intensive Care Med. 2008:34:511-7.

29. Choong K, Bohn D, Fraser DD, Gaboury I, Hutchison JS, Joffe AR, Litalien C, Menon K, McNamara P, Ward RE. Vasopressin in pediatric vasodilatory shock: a multicenter randomized controlled trial. Am J Respir Crit Care Med. 2009;180(7):632-9.

30. Agrawal A, Singh VK, Varma A, Sharma R. Intravenous arginine vasopressin infusion in refractory vasodilatory shock: a clinical study. Indian J Pediatr. 2012;79(4):488-93.

31. Rodríguez-Núñez A, Oulego-Erroz I, Gil-Antón J, Pérez-Caballero C, López-Herce J, Gaboli M, Milano G. Continuous terlipressin infusion as rescue treatment in a case series of children with refractory septic shock. Ann Pharmacother. 2010;44(10):1545-53.

32. Rodríguez-Núñez A, López-Herce J, Gil-Antón J, Hernández A, Rey C. Rescue treatment with terlipressin in children with refractory septic shock: a clinical study. Crit Care. 2006;10:R20.

33. Matok I, Vard A, Efrati O, Rubinshtein M, Vishne T, Leibovitch L, Adam M, Barzilay Z, Paret G. Terlipressin as rescue therapy for intractable hypotension due to septic shock in children. Shock. 2005;23(4):305-10.

34. Bidegain M, Greenberg R, Simmons C, Dang C, Cotten CM, Smith PB. Vasopressin for refractory hypotension in extremely low birth weight infants. J Pediatr. 2010;157(3):502-4.

35. Russell JA, Walley KR, Singer J, Gordon AC, Hébert PC, Cooper DJ, Holmes CL, Mehta S, Granton JT, Storms MM, Cook DJ, Presneill JJ, Ayers D. Vasopressin versus norepinephrine infusion in patients with septic shock. N Engl J Med. 2008:358:877-87.

36. Dünser MW, Mayr AJ, Ulmer H, Knotzer H, Sumann G, Pajk W, Friesenecker B, Hasibeder WR. Arginine vasopressin in advanced vasodilatory shock: a prospective, randomized, controlled study. Circulation. 2003;107:2313-9. 
37. Gaies MG, Jeffries HE, Niebler RA, Pasquali SK, Donohue JE, Yu S, Gall C, Rice TB, Thiagarajan RR. Vasoactive-inotropic score (VIS) is associated with outcome after infant cardiac surgery: an analysis from the pediatric cardiac critical care consortium (PC 4) and virtual PICU system registries. Pediatr Crit Care Med. 2014;15(6):529-37.

38. Gaies MG, Gurney JG, Yen AH, Napoli ML, Gajarski RJ, Ohye RG, Charpie JR, Hirsch JC. Vasoactive-inotropic score as a predictor of morbidity and mortality in infants after cardiopulmonary bypass. Pediatr Crit Care Med. 2010;11(2):234-8.

39. Tsuneyoshi I, Yamada H, Kakihana Y, Nakamura M, Nakano Y, Boyle W. Hemodynamic and metabolic effects of low-dose vasopressin infusions in vasodilatory septic shock. Crit Care Med. 2001;29(3):487-93.

40. Meyer S, Giannopoulou EZ. Vasopressin in arterial hypotension in extremely low birth weight infants. J Pediatr. 2015;167(2):498-9.

Submit your next manuscript to BioMed Central and we will help you at every step:

- We accept pre-submission inquiries

- Our selector tool helps you to find the most relevant journal

- We provide round the clock customer support

- Convenient online submission

- Thorough peer review

- Inclusion in PubMed and all major indexing services

- Maximum visibility for your research

Submit your manuscript at www.biomedcentral.com/submit
Biomed Central 